\title{
Civic technology for education: Analysis and evaluation of selected initiatives
}

\author{
Marta Majorek $^{1 \mathrm{a}}$, and Marta du Vall ${ }^{2}$ \\ ${ }^{1}$ Andrzej Frycz Modrzewski Cracow University, Poland \\ ${ }^{2}$ Andrzej Frycz Modrzewski Cracow University, Poland
}

\begin{abstract}
Civic Technology is defined (in general) as the use of information technology to engage local government and community residents in behaviors that improve the quality and accountability of public services, facilitate resident-driven improvements to local quality of life, and deepen participation in public decision-making and infrastructure maintenance. The drivers of Civic Technology in communities include technology-business entrepreneurs, civic hacking and local government efforts such as labs or think tanks. Authors present what civic tech actually is and confront theory with civic tech initiatives in education field. The main goal of the article is to explore the links between Civic tech and Education.
\end{abstract}

Keywords: Civic technology; education; civic tech initiatives

\section{What is civic technology?}

"For many, civic tech is the bridge between government's mission and modern technology's potential" [1]. Generally, civic tech is defined as use of information technologies to involve citizens, local communities and public administration bodies into operations that are intended to - among others - improve quality and clarity of public services, facilitate and improve citizens' life quality, increase the citizens' contribution to the public decision-making process, promote information sharing to develop the feeling of community, belonging and ownership. Civic tech's development is driven by entrepreneurs who operate in the tech industry, information activists and civic hackers, various think tanks and public authority entities [2]. It is the easiest to describe civic tech as the use of technology for the public benefit. "The underlying idea is that civic tech shares many of the characteristics of 21 rst century movements. That includes such elements as being mission driven, focusing on creating change that benefits the public and enabling more citizen input into decision making" [3]. Since such notions as an enterprise, public authority or think

\footnotetext{
a Corresponding author: marta@majorek.com
} 
tank should bring no doubts in terms of their definitions, it is worth taking a longer look at information-activism and civic hacking.

Currently, the term hacking should be employed to describe a phenomenon that embodies basic values of a networking society, i.e. passion, freedom, social value, openness, activity, concern and creativity [4]. It might be assumed that during development of any knowledge (in art, science, philosophy, culture, etc.), "everywhere where data can be collected, information can be compiled thereof, providing the world with new opportunities, there will be hackers hacking the new from the old" [5]. Along with development of new technologies and an increase in access (or even unlimited access) to the Internet, possibilities for use of hacking tactics and concepts have broadened [6]. It has been observed that they might be applied more widely than just the computers and networks. This fact brings extensive social consequences. A networked environment is a perfect platform for all actors, i.e. third sector's organizations, hobbyists, business environments, etc. It also ensures some space for new mechanisms allowing dispersed units to adopt decentralized strategies for cooperation. In such a system, the progress is of an incremental character, resulting from collection of (frequently) minor achievements of many persons, who decide independently what their subject of interest and actions is [7]. People may become a part of that "digital community" at a relatively small cost (it is enough to have a computer connected to the Internet, some initiative and creativity), thanks to which such an action becomes even more attractive [8]. "Civic hacking is nothing more as a way for social and economic advancement. It has already been known for some time that bottom-up, networking actions have the power to change the world, influence lives of others, among others through a direct contact established between a donor and an individual in need of support, help (according to the principle of mutuality). Currently, we are dealing with intensification of interactions and continuous development of communication related to development of a network society. This multiplicity of mutual relationships reduces the risk of alienation and anxiety, defeating the egoism of individuals. The more often people get in touch, the more common initiatives they undertake, and the more trust they put in each other. Changing and influencing the surrounding world is an activity that frees individuals and their potential. It combines two more natural needs of a man, which on one hand are the freedom of individual actions, and on the other the freedom to combine one's own efforts with those of other people and cooperate with them as a result" [9].

Information-activism, as stated in an article by Marta du Vall, should be comprehended as the ability to use the technology for creation, selection and sharing of information [10]. The information activists' objective is to provide people with information that help them make decisions in a conscious manner. Thus, it seems justified that information-activism is a sort of a form for informal education which adopts the democratic potential of the Internet, of other information and communication technologies and of new-type (i.e. virtual) societies, hence transforming the previously centralized social structures. Therefore, it is an activity that consists in improvement of awareness and advocacy through digital media [11].

Information-activism helps to mobilize individuals and motivate communities, thus revitalizing the notion of "community", changing its character and broadening the cognitive horizon. This is an action that forces involvement, participation in a civic society, social and political life. The activity is characterized with mutual trust, restraining from violence and respecting human rights. The main motif for inclusion of citizens into the social development is recognition of the right of all citizens to take part in the decision-making process related to their surroundings, as well as their opportunity to make independent decisions. The objective of information activists is to develop some varied media space, where you can hear different voices, and where everyone can report an event or express their opinion with a minimum editing intervention [12]. According to USDN Civic 
Technology Scan, there are three levels, which the civic-tech operates within: geospatial (global, regional, national, local), urban system (transport, energy, facilities, waste, water, safety, health, education, etc.), development of communities - neighbors, electorate, activists, service users, students, etc. [13].

We may also point to three categories of the civic tech users: public administration of various levels (e.g. local governments, state authorities), citizens (various communities), hackers (specialists that develop new tools, often making use of open data sources) [14]. "Investors, philanthropists, and the media see a gathering force, convergence of trends. The technology industry is increasingly interested in societal impact. Governments are developing the capacity to leverage advanced technologies. Communities are being expected to accomplish more with fewer resources" [15].

Therefore, we can state that Civic tech is where the public lends its talents, usually voluntarily, to help government do a better job [16].

" $<<$ Hackathons $>>$, meetings of software developers, entrepreneurs and government officials looking for new solutions to established problems during the course of a day or maybe a long weekend - are perhaps the most common example of civic tech, but the definition can be stretched to include any intersection of government cooperation with the public where the goal is to expand the role of the citizen in government's operations" [17]. Microsoft Corporation gathered hundreds of up-to-date examples of civic tech, and divided them into categories according to their functions. The result is a list of functional categories: crowdfunding platforms, benefit navigation tools, campaign organizing platforms, check-in tools, constituents of Government communication tools, crowdsourced data collection, data schemas and standards, data visualisation tools and platforms, event organizing tools, freedom of information tools, group communication tools, group decisionmaking tools, ideation tools, issue reporting platforms, mapping platforms, marketplaces and clearinghouses, neighborhood forums, online petition sites, open data publishing platforms, opinion matching platforms, resource matching/ sharing sites, sensors, service alerts, watchdogging and transparency projects [18].

Civic technology constitutes a change-making step, aiming to serve today's societies' sustainable progress and well-being [19]. It's clear that Civic Tech and education share many challenges and that Civic Tech should be adopted to improve education, and considered in activities undertaken by all actors responsible for educational projects. As we can read in post-event report from the CRI Open Class EdTech \#8-What education for what democracy? with François Taddei (Founder and Director of Centre for Research and Interdisciplinary), held on 10th of November 2016 - "Many of the existing educational systems remain limited; they only reproduce and $<<$ teach $>>$ the solutions of the past. However, our world's evolution follows a rather dynamic, nonlinear curve, within which new conditions create new challenges and needs. For this purpose, finding the solutions of tomorrow requires education that will train cooperative problem-solvers who think critically, re-combine, adapt and evolve existing knowledge, but most importantly $<<$ invent $>>$ a new approach that contributes to a sustainable solution for all" [20].

The problem with centralization and standardization is that they constitute objective rationality, which does not leave much space for reflecting upon action or for enabling teachers and students to explore issues through different perspectives. Such rationalization of education is specifically problematic in democratic countries, since it equates education with training students to achieve a mastery level in several subject matters, but neglects the need to develop autonomous individuals, who will have the capacities to make their present and future decisions in a critical and reasonable manner. There is an obvious need to prepare students for the 21 st century and move beyond standardization to develop creativity, civic values, and critical skills [21]. 
Due to the growing access to the Internet, new technologies and services, it is clear that today the younger generations are becoming more active in the online environment, and the use of the Internet does not bring any difficulties for them [22]. While thinking of the next generation's needs we should take into consideration the priorities of the re-invented education, and civic tech tools could act as facilitators and catalysts of this progress. As François Taddei pointed out: "one of the oldest and best "technologies" available to foster both engagement and education is discussion. Civic-tech tools inherit ideals of consensus and collective decision-making processes from the antique Greek "polis" through virtual discussions" [23] and "If one can build a Civic-Tech, EdTech, Open Science-Tech tool, one could invent new collective solutions, a much more open, fluid and inclusive debate. If it works, the mission will have contributed to creating a hybrid between Civic-Tech, EdTech and the future of knowledge technologies" [24].

\section{Civic tech applications in field of education}

According to Lea Douhard, civic tech is mainly considered as a tool for improvement of the "political fabric" (debates, concertation, legislative process, elections, etc.). She claims that "these new tools provide real empowerment of the civil society regarding the political system and the decision-making process; but they remain focused on the "traditional fields" of politics". She also proposes a hypothesis that "the democracy revolution will be sustainable and inclusive if and only if we go beyond the political agenda. Civic tech opened the door to a continuing citizen activity, over the long term, which imply new ways of teaching, learning, sharing and creation" [25]. Here, we should highlight and discuss some examples of applying the civic tech in education, with particular focus on discussing educational platforms ran by recognized university units, such as Harvard or MIT.

Civic tech can be first seen as the future of libraries. It's all about thinking wisely about those things that librarians know for certain, i.e. what a community wants and how to create an ideal place for everyone. This can happen when libraries "dig deep to understand community needs at the local and neighborhood level, and develop collections, programs, facilities and services to meet those needs" [26]. That's why libraries of all sizes serving all types of communities should choose civic technologies as one of their main tool. Civic tech experts "can help use libraries data that can support libraries in their getting connected with customers, finding more of them, and providing them with what they need and want" [27].

An example of civic technology that works for libraries is CommunityConnect. It "is a web-software solution that integrates data from (...) a library with market segmentation, demographic, and other data so [it] can better understand (...) community, predict what people are interested in, and deliver relevant services to them". [28].

As we can read on the web page, use of the above-mentioned software allows "customers to effectively execute cardholder development campaigns, make smarter decisions on collection expansion, determine the need and find the best sites for new locations, plan programs and services, match staff to meet community needs, plan facility improvements, develop consumer technologies, and invest in effective marketing and communications campaigns" [29].

CommunityConnect website offers some examples for using its service. Libraries staff report that "they have learned much about their communities and that what they've learned is reflected in actionable activities" and that "the more they study the data the more they learn". Users pay attention to the fact that CommunityConnect software provides the opportunity to present critical insights into community literacy conditions [30].

Another example of a civic tech app is Rafter [31]. It adopts cloud-based e-textbooks and course materials, helping campus bookstores digitize their offerings and keep their prices low, allowing them to regain the market share they were losing to other stores and 
course-materials marketplaces. In this solution - it the school wins because store revenues rise and the students win because course materials are cheaper. We cannot forget about Rafter itself who wins boasting with the results in convincing win-win customer testimonials [32]. Rafter is an all-inclusive solution that allows schools to include textbooks as an item on the student's bill. By adopting Rafter, colleges provide students with all of their assigned course materials on day one for a low and predictable flat rate[33].

As Paul Toler, Vice President of Finance at Avila University, pointed out "Rafter gave us the freedom to select both on-campus pickup and direct-to-student distribution, enabling us to put books in the hands of all students. We're looking forward to seeing the improvements we anticipate in the results." [34].

It is worth mentioning some other civic tech projects in the field of education like Quizlet, Coursera, edX, Udacity and many others that are excellent illustrations for implementation of innovative projects aimed at adapting the learning process to today's requirements. Quizlet is a popular platform that enables teachers to design quizzes, which provide several options to help students to memorize terms and concepts. For example, teachers can add flash cards for a specific class unit. The students review the concept, and once they click on a flashcard, an explanation of a given concept appears. A common use of Quizlet is a match game, in which students need to match the concept with its correct definition. This can be used for competing between individual students or groups. During classes I observed that teachers used this tool mainly for group competition. University of Michigan offered courses published on a start-up platform called Coursera. The company promotes massive online open courses - known as MOOCs. An interesting initiative is also a nonprofit venture founded by the Harvard and the Massachusetts Institute of Technology - edX that features 26 classes, including "Quantum Mechanics and Quantum Computation". Learning Labs for Cities: A Virtual Civic Tech Series is an initiative which is developing a virtual learning platform where government leaders can learn and share content as peers focused on civic technology and emerging areas of innovation. The Learning Labs will provide communities with specially curated resources from the higher education ecosystem via a relationship with edX. The main goal of the project is to facilitate an online learning environment where best practices about emerging innovation can be shared [35].

Another competitor among civic tech initiatives is Udacity. Backed by venture capitalists, it was established by Sebastian Thrun, an acclaimed computer science professor, after more than 160,000 students had taken part in his online artificial-intelligence course at Stanford University. He thinks Udacity will ultimately increase enrollment at brick-andmortar institutions by preparing more underserved high school students for college [36]. For the universities that create free online courses, mainly major colleges with A-plus brands, relationships with Coursera, Udacity and edX could be beneficial. Mega classes, which can draw hundreds of thousands of students, may aid faculty retention, providing a perk for star professors. And all MOOC marketers promise to share revenues with partner universities, although the path to profitability is murky. The future is brighter for students, whether they choose to continue education or not. As colleges start to give loans to students who complete MOOCs, market forces will pressure many other institutions to liberalize their credit-transfer policies, bringing educational costs down [37].

Most of the popular sites charge a subscription fee while leaving some portion of their offerings free to the public. Course Hero collects a charge of \$20 monthly from students, who are willing to access its offerings, although they can skip the monthly charge by uploading at least 30 documents useful to peers, such as class notes or graded tests. Most of Cramster's offerings are free of charge, but the site collects about $\$ 10$ a month or $\$ 50$ per year for a premium membership entitling students to gain broader access and have a shorter response time on message boards. In some cases, even professors used the sites. For 
example, professor David Choi, who gives entrepreneurship classes at Loyola Marymount University College of Business in Los Angeles, conducted a course on product development devoted to students enrolled at two different colleges. He uploaded class materials to the Course Hero platform, so students from both schools could easily access the same files. This shows that information technology dramatically affects how we do business now, including teaching. In academia nowadays, the sharing of information is generally much more ubiquitous, as more professors shift to open courseware publishing or wiki models where multiple writers can contribute. Yale and MIT now post all course materials online. The traditional model of university teaching assumes that we are the givers of information, so we need to move to a model where different sorts of information available are addressed and students need to learn to be critical consumers of information [38].

\section{Conclusion}

Fostering democratic citizenship and having informed citizens requires public education that advocates public interests and prepares students to be critical, reflective, sensitive, and active citizens. For example, students ought to understand how the legal, political, and economic systems work, as well as become aware of the ways in which they can and should be involved in issues concerning the public good [39]. Cultural discourses aim to reconsider hegemonic cultural assumptions, such as "the common culture," and suggest that acknowledging cultural difference is essential for attaining an inclusive and vibrant democratic society [40]. The meaning of this in terms of digital technology is that rather than reproducing cultural conventions, digital technology holds the potential for students to be exposed to and to experience different cultures.

Today, we are living in the world where culture is mediated through the Internet, blogs, social media, video communication software, and other communicative platforms. Instead of reinforcing predetermined cultural narratives, educators can help students to encounter cultural differences, reflect upon them, and realize the cultural challenges, as well as the possible opportunities open for them as individuals and as members of society. In addition, teachers and students need to recognize the potential of digital tools to engage in transformative online spaces, which struggle for equity, equality, and the betterment of the common good. Moreover, the discussion can continue beyond the limited time of the class. Students can discuss the issue in the class forum or in social media beyond the boundaries of the classroom. They can also compare how other countries treat similar issues. The key here is to avoid (resist directing students towards) an instant answer after a short class discussion that hardly scratches the surface. The purpose is rather to challenge students to encounter different views and to reconsider the issue through various lenses. This can help students to link the curricular content with the world, gradually helping them to develop their critical and reflective understanding of different situations, to shape their positions about them, and to imagine what might be the desired society in which they aspire to live. Digital citizenship involves the nexus of inclusive democracy, critical literacy, and realization of the nature of digital technology. I deem this framework useful for moving beyond technical and functional understanding of digital technology and for supporting teachers and students in utilizing digital devices in a more complete and meaningful way. Recognizing the nature of technology is necessary for demystifying the biases of digital design and placing them in a social context. Becoming aware of social conditions is an inevitable step to create active agency and move towards social transformation [41].

Undoubtedly, the impact exerted by the strong advocates on development of civic tech is limited to countries with advanced technological development, with highly developed instruments and democratic institutions. Majority of presented examples come from 
countries such as the USA, UK, the Netherlands, where Civic Tech is an environment where only individuals but also many national and local NGOs are strongly engaged. Significant involvement is also evident at the universities of different specializations, in representatives of government agencies and plenty of different levels of government, representatives of organizations and institutions that care about specific parts of the public domain such as information, education, environment, social support. The most famous place in Poland that brings Civic Tech together is the Code for Poland, run under the aegis of the Foundation of the Republic. The first is the large and resilient American Code for American organizationa. There are also smaller groups that can collaborate on specific projects. There may be many informal groups that are small enough to still be difficult to identify. Unfortunately, so far, the Polish environment is hardly represented by the academic world and public administration, but it is also slowly changing. This clearly demonstrates that only the integrated actions of numerous institutions can exert significant and noticeable impact on modifying educational assumptions and changing the existing model that is currently unable to meet the challenges of the 21 st century.

\section{References}

1. C. Wood, What is Civic Tech?, http://www.govtech.com/civic/What-is-CivicTech.html (29.05.2017)

2. The Civic Technology Landscape: A Field Analysis and Urban Sustainability Directors Network Recommendation,(A USDN Innovation Fund Scan, 07.2015)

3. A.Field, Why There Isn't More Of A Hullabaloo About Civic Tech https://www.forbes.com/sites/annefield/2016/06/11/why-there-isnt-more-of-ahullabaloo-about-civic-tech/\#3b60ed322989 (30.05.2017)

4. T. Jordan, Hakerstwo, (Warsaw, 2011)

5. W. McKenzie, A Hacker Manifesto (Cambridge 2004)

6. A. Harper, Gray hat hacking: the ethical hacker's handbook (New York, 2011)

7. Y. Benkler, Bogactwo sieci. Jak produkcja spoleczna zmienia rynki $i$ wolność (Warsaw, 2008)

8. D. Tapscott, A.D. Williams, Wikinomia. O globalnej wspótpracy, która zmienia wszystko (Warsaw, 2008)

9. M. du Vall, Obywatelski hacking jako implikator zmian społecznych w XXI wieku, [in] Demokracja elektroniczna. Kontrowersje i dylematy, ed. M. Marczewska-Rytko (Lublin, 2013)

10. M. du Vall, Infoaktywizm. Strategie komunikacyjne społeczników ery cyfrowej, [in] Haktywizm, ed. M. Marczewska-Rytko (Lublin 2014)

11. J. Nowak, Aktywność obywateli online. Teoria i praktyka (Lublin, 2011)

12. L.A. Lievrouw, Media alternatywne i zaangażowane społecznie (Warsaw 2012)

13. The Civic Technology Landscape: A Field Analysis and Urban Sustainability Directors Network Recommendation, (A USDN Innovation Fund Scan 07.2015)

14. Ibid.

15. Towards a taxonomy of civic technology https://blogs.microsoft.com/on-theissues/2016/04/27/towards-taxonomy-civictechnology/\#sm.0000npt3rosvxfn2t9g11oloc8iwh (1.06.2017)

16. C. Wood, What is Civic Tech?, http://www.govtech.com/civic/What-is-CivicTech.html (29.05.2017)

17. Ibid.

18. Towards a taxonomy of civic technology https://blogs.microsoft.com/on-theissues/2016/04/27/towards-taxonomy-civic- 
technology/\#sm.0000npt3rosvxfn2t9g11oloc8iwh (1.06.2017)

19. E. Maraitopoulou, Civic Tech and tomorrow's Education, https://medium.com/openedtech/civic-tech-and-tomorrows-education-e79a87eedcf0 (1.06.2017)

20. Ibid.

21. D. Mamlok, Digital Technology and Education in the Age of Globalization (Doctoral dissertation, Miami University 2017)

22. J. Wojniak, M. Majorek, Children in internet space - the European Union policies on children's safety online, SHS Web of Con. 26, 01048 (2016)

23. A. Jahn, Civic-Tech and tomorrow's education: An Open Class with François Taddei https://medium.com/@anthony.jahn/civic-tech-and-tomorrows-education-an-openclass-with-fran\%C3\%A7ois-taddei-91f76b735529 (30.05.2017)

24. Ibid.

25. L. Douhard, When Civic Tech meets Education \& Culture (2016)

https://forum.etalab.gouv.fr/t/when-civic-tech-meets-education-culture/2250

26. http://civictechnologies.com/

27. Ibid.

28. Ibid.

29. Ibid.

30. Ibid.

31. Rafter http://www.rafter.com/ (2.06.2017)

32. I. Mochari, 16 Startups Poised to Disrupt the Education Market https://www.inc.com/ilan-mochari/16-startups-that-will-disrupt-the-educationmarket.html (2.06.2017)

33. Jenzabar Partners with Rafter to Prepare Students for Success, https://www.jenzabar.com/blog/2016/05/25/jenzabar-partners-rafter-prepare-studentssuccess/ (2.06.2017)

34. Avila University Partners With Rafter to Provide Students With $100 \%$ of Required Course Materials to Improve Student Outcomes http:/www.marketwired.com/pressrelease/avila-university-partners-with-rafter-provide-students-with-100-requiredcourse-2163711.htm (2.06.2017)

35. Civic Innovation Project, http://www.civicinnovationproject.com/contact

36. D. Wallis, Colleges assess cost of free online-only courses. The New York Times, 18 (2013)

37. Ibid.

38. A. Chaker, Do Study Sites Make the Grade. The Wall Street Journal (April 9, 2009)

39. K. Robinson, Creative schools. (2015)

40. K. Knight-Abowitz, Publics for public schools: Legitimate, democracy, and leadership. (2013)

41. D. Mamlok, Digital Technology and Education in the Age of Globalization (Doctoral dissertation, Miami University, (2017) 